\title{
EFISIENSI SEBAGAI BASIS KEBIJAKAN PENYELENGGARAAN PERUMAHAN RAKYAT ${ }^{1}$
}

\author{
Erica Soeroto ${ }^{2}$ \\ Konsultan Independen Pembiayaan Perumahan
}

\begin{abstract}
Compared to other countries, housing financing in Indonesia is relatively left behind. In Indonesia, housing financing is dominantly by banking's mortgage loan. Furthermore, the ratio of home loan to GDP of the country is still insignificant. If we compare to other countries' banking sector, Indonesia's banking sector is less efficient. This could be observed from the interest rate spread of the banking sector. This article argues that, housing policy in Indonesia should focus on improving housing financing efficiency through: efficient primary housing financing, liquid and stable bond market, and supporting regulation based on cost and benefit analysis; in order to provide affordable housing for low income people in Indonesia.
\end{abstract}

Keywords: housing financing; housing policy; banking sector efficiency; Indonesia

\begin{abstract}
ABSTRAK
Dibandingkan negara lain, pembiayaan perumahan di Indonesia masih tertinggal. Pembiayaan perumahan di Indonesia sebagian besar masih mengandalkan Kredit Pemilikan Rumah (KPR) dari perbankan. Selanjutnya, rasio KPR terhadap PDB di Indonesia masih sangat kecil. Jika kita bandingkan dengan negara-negara lain, Lembaga perbankan Indonesia belum dapat dikatakan efisien. Hal tersebut dapat dilihat dari perbedaan antara tingkat suku bunga pinjaman dan tingkat suku bunga simpanan di sektor perbankan (interest rate spread). Penulis berpendapat bahwa kebijakan pembiayaan perumahan di Indonesia harus menitikberatkan pada peningkatan efisiensi lewat: pembiayaan perumahan primer yang efisien, ketersediaan pasar obligasi yang likuid dan stabil, serta peraturan yang mendukung berdasarkan analisis biaya dan manfaat, demi tersedianya tempat tinggal bagi masyarakat berpenghasilan rendah (MBR).
\end{abstract}

Kata kunci: pembiayaan perumahan; kebijakan perumahan; efisiensi sektor perbankan; Indonesia

\section{PEMBIAYAAN PERUMAHAN}

Sejak terbitnya Undang-Undang (UU) Perbankan tahun 1992, pasar keuangan di Indonesia didominasi oleh perbankan. Setelah krisis tahun 1997 arah kebijakan di bidang perbankan diutamakan untuk menyelamatkan sistem perbankan dan meningkatkan fungsi pengawasan dengan pembatasan ruang gerak perbankan terhadap kemungkinan terlibat dalam perilaku spekulatif, untuk mencegah terulangnya krisis (Bank Indonesia, n.d.).

Dominasi perbankan juga terjadi dalam pembiayaan perumahan. Namun demikian, jika dibandingkan dengan negara-negara lain, pembiayaan perumahan melalui lembaga bank di

\footnotetext{
1 Intisari makalah ini disampaikan pada Expert Meeting Perumahan Rakyat "Memberi Arah Kebijakan Pembangunan Perumahan Rakyat", diselenggarakan oleh Sub-Direktorat Standar dan Pedoman, Direktorat Rumah Umum dan Komersial Direktorat Jenderal Penyediaan Perumahan, Kementerian Pekerjaan Umum dan Perumahan Rakyat, bertempat di Galeri Arsitektur, Institut Teknologi Bandung, 11 April 2018.

${ }^{2}$ Kontak penulis: erica.soeroto@yahoo.com
} 
Indonesia hingga saat ini masih tertinggal. Volume kredit perumahan rakyat (KPR) jika dibandingkan dengan Produk Domestik Bruto (PDB) masih relatif kecil. Di antara negara berkembang di Asia, pasar pembiayaan perumahan di Indonesia termasuk yang paling terbelakang. Data tahun 2012 sampai 2016 menyebutkan, rasio KPR terhadap PDB untuk Indonesia masih di bawah tiga persen, jauh tertinggal bahkan dari negara-negara Asia lain; apalagi jika dibandingkan dengan negara-negara maju seperti Amerika Serikat (lihat Tabel 1). Sampai tahun 2017 angka tersebut tidak bergeser banyak, masih jauh bahkan jika dibandingkan negara-negara tetangga di Asia Tenggara, seperti Malaysia, Singapura, dan Thailand (Kompas.com, 2017).

Tabel 1. Rasio KPR terhadap PDB di beberapa Negara (dalam \%)

\begin{tabular}{lccccc}
\hline \multicolumn{1}{c}{ Negara } & $\mathbf{5}$ & Tahun \\
\cline { 2 - 6 } Indonesia & $\mathbf{2 0 1 2}$ & $\mathbf{2 0 1 3}$ & $\mathbf{2 0 1 4}$ & $\mathbf{2 0 1 5}$ & $\mathbf{2 0 1 6}$ \\
\hline Brunei & 2,57 & 2,88 & 2,99 & 2,94 & 2,95 \\
\hline Malaysia & 3,82 & 4,42 & 4,45 & 5,61 & 6,36 \\
\hline Filipina & 31,29 & 33,85 & 33,92 & 36,11 & 36,66 \\
\hline Thailand & 2,34 & 2,61 & 3,01 & 3,19 & 3,47 \\
\hline Singapura & 10,88 & 11,72 & 12,82 & 13,50 & 13,65 \\
\hline India & 41,84 & 43,72 & 45,81 & 44,86 & 45,50 \\
\hline Jepang & 5,02 & 5,29 & 5,70 & 6,06 & 5,95 \\
\hline Korea Selatan & 47,18 & 47,67 & 47,82 & 47,24 & 48,08 \\
\hline USA & 21,98 & 21,92 & 23,13 & 19,76 & 19,21 \\
\hline Sumy & 58,82 & 56,37 & 53,95 & 52,79 & 52,83 \\
\hline
\end{tabular}

Sumber: OECD dan bank sentral masing-masing negara berbagai tahun

Rendahnya KPR terutama karena terbatasnya akses dana ke pasar modal, dan tingkat suku bunga yang fluktuatif, di satu sisi; sementara harus diakui bahwa sebagian besar tenaga kerja dari masyarakat berpenghasilan rendah (MBR) berasal dari sektor informal, sehingga mereka tidak dapat menjangkau pembiayaan formal. Bahkan bagi masyarakat berpenghasilan menengah, KPR belum berfungsi dengan baik. Suka atau tidak suka, kita harus menerima kenyataan bahwa selama sistem pembiayaan perumahan belum berhasil memenuhi kebutuhan perumahan bagi masyarakat berpenghasilan menengah, maka masalah pembiayaan perumahan bagi masyarakat berpenghasilan rendah (MBR) sulit untuk diatasi (Diamond, 1997; Eldin et al., 2004). Oleh karena itu, pemerintah harus berupaya mempromosikan efisiensi pasar. Upaya ini penting karena pengembangan sektor perumahan merupakan bagian yang tidak terpisahkan dari pembangunan ekonomi.

Perumahan merupakan mesin penggerak pertumbuhan ekonomi dan memegang peran utama dalam stabilitas sistem keuangan. Sektor perumahan, yang merupakan bagian terbesar dari ekonomi menjadi amat penting karena memiliki multiplier effect, menjadi sarana bagi rumah tangga untuk akumulasi kekayaan demi hari tua, memperluas lapangan kerja, meningkatkan penerimaan pajak dan memberi kontribusi positif terhadap stabilitas ekonomi. Jika pertumbuhan KPR terbelenggu, maka akan menghasilkan multiplier effect yang negatif, artinya, selain mencemari pasar keuangan lainnya juga dapat meningkatnya pengangguran dan kemiskinan (Cardin et al., 1976). Dampak negatif ini akhirnya menjadi beban pemerintah, karena harus menanggung biaya yang timbul karena terbatasnya hunian seperti permukiman kumuh, pemberantasan kriminalitas. Oleh karena itu, menciptakan pasar perumahan yang kuat dan sehat sangat penting untuk menghasilkan sumber daya yang diperlukan untuk mengurangi kemiskinan. 
Penyediaan rumah tidak terlepas dari pembiayaannya, sebab rumah merupakan barang yang harganya sangat mahal jika dibandingkan dengan pengeluaran rumah tangga lainnya. Sistem pembiayaan perumahan merupakan seluruh kegiatan yang bertujuan untuk mengalirkan dana dari pihak yang memiliki kelebihan dana kepada kepada pihak yang memerlukan dana dengan cara yang efisien dan efektif. Kebijakan yang bertujuan meningkatkan efisiensi pembiayaan perumahan dapat dilakukan melalui tiga hal, yaitu: tersedianya pasar pembiayaan perumahan primer yang efisien, tersedianya pasar obligasi yang aman dan stabil dan likuid, serta dukungan peraturan yang disusun dengan mempertimbangkan biaya dan manfaat (Arner, 2002).

\section{EFISIENSI PASAR PEMBIAYAAN PERUMAHAN PRIMER}

Sebelum tahun 1997, sektor perumahan di banyak negara berkembang, menduduki prioritas rendah dalam perencanaan pembangunan. Kebijakan dan regulasi yang mendukung program perumahan bagi masyarakat berpenghasilan rendah sering salah arah dan tidak efisien sehingga lebih banyak dinikmati oleh masyarakat yang berpenghasilan menengah. Regulasi di sektor jasa keuangan, terutama di sektor perbankan, cenderung konservatif dengan fokus pada perlindungan konsumen dan pencegahan kegagalan (Cardin, et al., 1976). Namun dalam dua dekade terakhir terjadi perubahan yang mendasar terkait pengaturan dan pengawasan pasar pembiayaan perumahan. Pembatasan kredit telah diperlunak atau dihapus karena pemerintahan negara yang bersangkutan telah mempertimbangkan kembali kerangka regulasi sebagai landasan hukum beroperasinya lembaga keuangan. Fokus kerangka regulasi di sebagian negara termasuk Korea, telah bergeser menjadi lebih liberal, dari pengaturan yang kaku dan ketat diganti dengan efisiensi melalui peningkatan disiplin pasar, supervisi dan pengelolaan risiko serta membuka akses pendanaan dari pasar modal (Green dan Wachter, 2007).

Tabel 2. Rasio KPR terhadap Total Kredit Perbankan di Indonesia, 2008 - 2016

\begin{tabular}{cccc}
\hline Tahun & Saldo KPR & Kredit Perbankan & Rasio (\%) \\
\hline 2008 & 100.950 & 1.307 .688 & 7,72 \\
\hline 2009 & 115.233 & 1.437 .930 & 8,01 \\
\hline 2010 & 140.599 & 1.765 .844 & 7,96 \\
\hline 2011 & 176.659 & 2.200 .094 & 8,03 \\
\hline 2012 & 211.476 & 2.707 .862 & 7,81 \\
\hline 2013 & 268.764 & 3.292 .874 & 8,16 \\
\hline 2014 & 302.916 & 3.674 .308 & 8,24 \\
\hline 2015 & 326.327 & 4.057 .904 & 8,04 \\
\hline 2016 & 353.648 & 4.377 .195 & 8,08 \\
\hline
\end{tabular}

Sumber: Stastistik Perbankan Indonesia (SPI) dan Statistik Ekonomi dan Keuangan Indonesia (SEKI), diolah (berbagai tahun)

Setelah krisis ekonomi tahun 1998, Indonesia menggunakan pendekatan yang berbeda, namun ternyata hal tersebut menciptakan iklim yang tidak kondusif untuk pertumbuhan KPR. Meskipun daya tarik penyaluran KPR di beberapa negara Asia semakin meningkat, namun di Indonesia masih banyak perbankan yang enggan memasuki pasar. Masih ada keragu-raguan karena kekhawatiran tentang kemampuan mengelola risiko. Selain itu masih ada kelemahan dalam bidang penyertifikatan tanah, pembebanan agunan, lelang agunan dan penyitaan, tingginya beban pajak. Keterbatasan penyaluran KPR memberi dampak negatif yang signifikan pada efisiensi investasi perkotaan, penerimaan pajak serta akumulasi kesejahteraan masyarakat 
88 | Bina Ekonomi

dan makroekonomi.

Pasar pembiayaan primer merupakan pasar tempat dilakukan penyaluran KPR. Pasar pembiayaan primer dikatakan efisien, antara lain jika telah mencapai tahap pertumbuhan yang matang, sehingga mampu memproduksi KPR dalam jumlah besar oleh berbagai jenis lembaga penyalur KPR secara berkelanjutan. Sementara di Indonesia, KPR belum berkembang. Hal tersebut dapat dilihat dari rasio KPR terhadap PDB dan rasio KPR terhadap total kredit perbankan. Tabel 1 menunjukkan, volume KPR di Indonesia masih di bawah tiga persen PDB; sedangkan rasio KPR terhadap total kredit perbankan juga masih di bawah 10\% (lihat Tabel 2).

Pasar yang efisien dapat menawarkan beragam produk KPR sesuai kebutuhan konsumen dan dapat memperluas jangkauan ke segmen masyarakat yang berpenghasilan tidak tetap. Pengalaman internasional menunjukkan bahwa lembaga keuangan bukan bank khusus (Specialized Non-Bank Financial Institution) yang fokus kegiatannya hanya menyalurkan kredit untuk sektor tertentu dan untuk target masyarakat tertentu. Namun, lebih sesuai untuk menyalurkan KPR dibanding bank, karena memiliki keahlian yang lebih tinggi, dan lebih mengenal nasabahnya sehingga lebih mudah merancang produk yang sesuai kebutuhan konsumen (Carmichael dan Pomerleano, 2002). Lembaga semacam ini di Indonesia sudah tidak dikenal sejak diterbitkannya UU Perbankan tahun 1992.

Pasar primer yang efisien juga dapat dilihat dari selisih antara tingkat suku bunga simpanan dan tingkat bunga KPR. Untuk perbandingan antar-negara, selisih tingkat suku bunga dapat diwakili oleh data selisih antara rata-rata tingkat suku bunga simpanan dan rata-rata tingkat suku bunga pinjaman, atau yang disebut sebagai interest rate spread. Data menunjukkan bahwa interest rate spread di Indonesia relatif lebih tinggi dibandingkan dengan negara-negara tetangganya (lihat Tabel 3), menandakan bahwa sektor perbankan Indonesia masih dapat ditingkatkan efisiensinya. Penyebab tingginya tingkat suku bunga pinjaman (dalam hal ini termasuk KPR) perlu ditelaah sebelum penerapan kebijakan subsidi bunga.

Tabel 3. Interest Rate Spread Beberapa Negara Asia (dalam \%)

\begin{tabular}{lcccccccc}
\hline \multicolumn{1}{c}{ Nama Negara } & $\mathbf{2 0 0 9}$ & $\mathbf{2 0 1 0}$ & $\mathbf{2 0 1 1}$ & $\mathbf{2 0 1 2}$ & $\mathbf{2 0 1 3}$ & $\mathbf{2 0 1 4}$ & $\mathbf{2 0 1 5}$ & $\mathbf{2 0 1 6}$ \\
\hline China & 3,06 & 3,06 & 3,06 & 3,00 & 3,00 & 2,85 & 2,85 & 2,85 \\
\hline Jepang & 1,29 & 1,10 & 1,04 & 0,93 & 0,76 & 0,80 & 0,74 & 0,74 \\
\hline Indonesia & 5,22 & 6,24 & 5,47 & 5,85 & 5,39 & 3,85 & 4,33 & 4,72 \\
\hline Malaysia & 3,00 & 2,50 & 2,00 & 1,81 & 1,64 & 1,54 & 1,45 & 1,52 \\
\hline Filipina & 5,83 & 4,45 & 3,28 & 2,52 & 4,11 & 4,30 & 3,99 & 4,05 \\
\hline Thailand & 3,75 & 3,13 & 2,61 & 2,59 & 2,63 & 3,20 & 3,30 & 3,17 \\
\hline
\end{tabular}

Sumber: World Bank (data.worldbank.org)

\section{PASAR OBLIGASI YANG LIKUID DAN STABIL}

Sifat KPR adalah jangka panjang, dan jumlah dana jangka panjang yang diperlukan cukup besar sebab harga rumah yang relatif mahal dibandingkan dengan pengeluaran rumah tangga lainnya. Oleh karena itu, untuk memfasilitasi kebutuhan perumahan diperlukan sistem pembiayaan perumahan yang efisien untuk menyediakan sumber pendanaan bagi masyarakat untuk membeli rumah. Ketersediaan sumber dana jangka panjang yang berkelanjutan dapat mendorong terbentuknya sistem keuangan negara yang sehat dan efisien dan memberi kontribusi positif bagi pertumbuhan ekonomi (Laeven, 2014). Selain sektor perbankan, obligasi adalah salah satu sumber pendanaan pembiayaan perumahan. 
Pasar obligasi Indonesia masih belum berkembang jika dibanding dengan negara-negara Asia lain. Hal tersebut dapat dilihat dari peran obligasi sebagai sumber pembiayaan, baik di sektor publik (pemerintah) maupun sektor swasta. Pada tahun 2015, rasio kapitalisasi obligasi terhadap PDB Indonesia hanya 15\%, masih di bawah negara-negara Asia lainnya (lihat Tabel 4). Ketika pasar belum berkembang, maka kesempatan untuk memanfaatkan sumber pendanaan yang tersedia menjadi terbatas. Perkembangan pasar obligasi korporasi terhambat antara lain karena dibatasi oleh persyaratan investasi yang ketat, tingginya biaya penerbitan dan proses yang relatif lama (World Bank, 2014). Keterbatasan peran obligasi juga berarti belum tercapainya skala ekonomis untuk menghasilkan likuiditas pasar dalam jumlah yang memadai.

Tabel 4. Rasio Kapitalisasi Obligasi terhadap PDB di Beberapa Negara Asia (dalam \%)

\begin{tabular}{lcccccc}
\hline \multicolumn{1}{c}{ Desember 2000 } & \multicolumn{4}{c}{ Desember 2015 } \\
\hline Negara & Pemerintah & Swasta & Total & Pemerintah & Swasta & Total \\
\hline Hongkong & 16,59 & 0,29 & 16,88 & 39,02 & 19,99 & 59,01 \\
\hline Indonesia & 8,12 & 27,16 & 35,28 & 38,72 & 29,07 & 67,79 \\
\hline Jepang & 35,39 & 1,36 & 36,75 & 13,00 & 2,16 & 15,16 \\
\hline Korea Selatan & 78,52 & 23,63 & 102,16 & 199,26 & 15,80 & 215,06 \\
\hline Malaysia & 25,66 & 48,78 & 74,44 & 52,74 & 76,90 & 129,64 \\
\hline Filipina & 38,05 & 35,21 & 73,26 & 52,86 & 43,84 & 96,70 \\
\hline Singapura & 31,05 & 0,22 & 31,27 & 29,65 & 6,12 & 35,77 \\
\hline Thailand & 26,60 & 20,91 & 47,51 & 45,52 & 32,22 & 77,74 \\
\hline Vietnam & 22,82 & 4,54 & 27,36 & 55,38 & 18,60 & 73,98 \\
\hline \multicolumn{1}{c}{ Sum } & 0,28 & 0,00 & 0,28 & 21,53 & 0,71 & 22,24 \\
\hline
\end{tabular}

Sumber: AsiaBondsOnline

Perusahaan yang memerlukan dana untuk pengembangan usahanya, mempunyai pilihan, menggunakan dana sendiri atau memanfaatkan dana perbankan seperti kredit jangka pendek, menengah, kredit sindikasi, atau dana pasar modal seperti obligasi korporasi dan mengeluarkan saham. Obligasi korporasi menawarkan arus kas yang dapat diprediksi baik oleh emiten maupun investor, pembayaran bunga yang teratur dan pengembalian pokok pada saat obligasi jatuh tempo.

Saat ini, pasar keuangan didominasi perbankan yang memiliki daya ungkit yang tinggi sehingga sektor keuangan yang bergantung pada perbankan, akan lebih rentan terhadap krisis (Bhattacharyay, 2011). Salah satu sebab terjadinya krisis keuangan di Asia tahun 1997-1998 adalah ketergantungan sektor ekonomi terhadap dana perbankan dan pinjaman luar negeri. Ketika itu, sumber dana untuk menggerakkan perekonomian dan investasi sektor swasta, hanya berasal dari perbankan sehingga tidak tersedia keterbukaan informasi tentang risiko nilai tukar, suatu hal yang penting untuk melindungi sektor usaha (Eichengreen dan Hausmann, 1999). Oleh sebab itu, dibutuhkan diversifikasi sumber dana dalam negeri dalam jumlah besar dan kebutuhan ini akan terus berkembang untuk mencapai sasaran pertumbuhan ekonomi.

Jika kita perhatikan, pembiayaan domestik di Indonesia didominasi oleh ekuitas. Peran obligasi masih kecil. Data tahun 2013 menunjukkan, hanya 12,29\% pembiayaan dpmestik di Indonesia didapat dari obligasi; jumlah ini termasuk kecil jika dibandingkan dengan negaranegara lain (lihat Gambar 1). Oleh karenanya, potensi untuk mengembangkan pasar obligasi di Indonesia masih terbuka lebar. 
Gambar 1. Profil Pembiayaan Domestik: Kredit, Obligasi, dan Ekuitas (2013) (dalam \%)

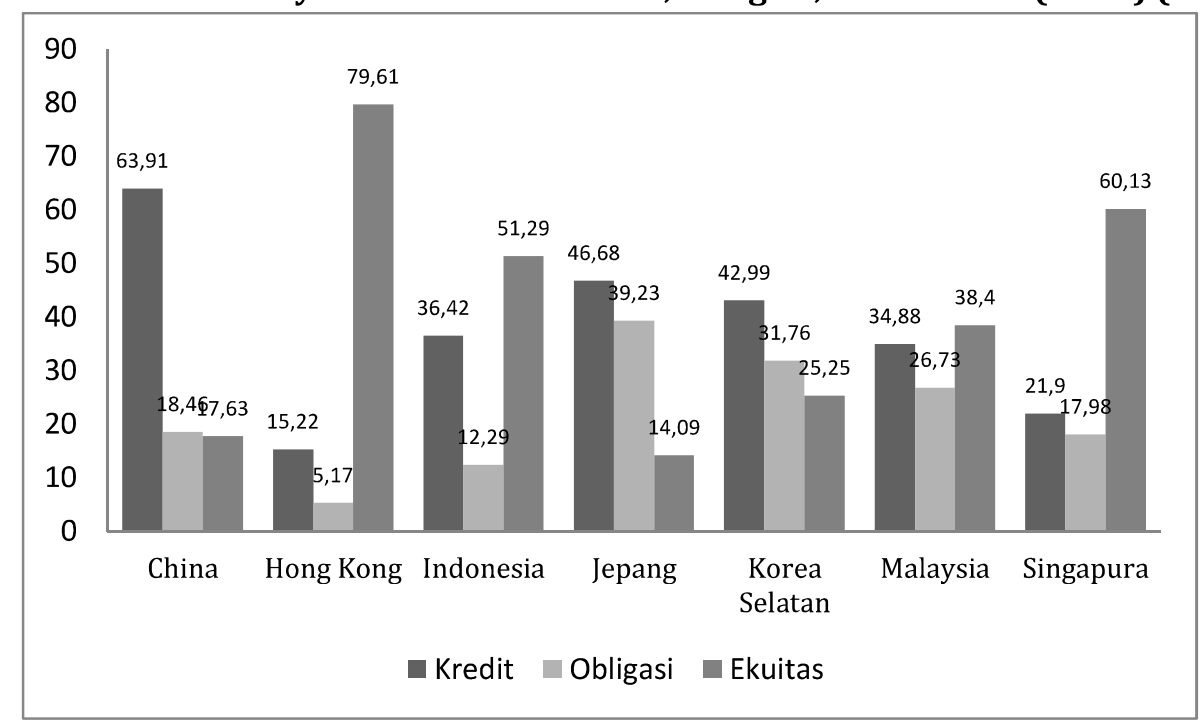

Sumber: Asiabondonline

Jika pasar obligasi berkembang, maka akan tersedia dana jangka panjang sebagai pendamping dana perbankan yang berjangka pendek. Pasar obligasi yang berkembang dapat memberikan fasilitas penempatan dana pada obligasi dalam mata uang domestik, membatasi ketidaksesuaian jatuh tempo pada neraca perusahaan dan memperkuat perekonomian agar lebih tahan dalam menghadapi guncangan.

\section{DUKUNGAN REGULASI}

Iklim untuk pertumbuhan KPR terutama dipengaruhi oleh regulasi dan kebijakan masa lalu serta stabilitas ekonomi. Pertumbuhan KPR senantiasa menjadi perhatian pemerintah karena memiliki kontribusi pada pertumbuhan ekonomi yang tercermin pada rasio PDB. Selain meningkatkan efisiensi pasar pembiayaan perumahan primer dan memperkuat pasar obligasi agar menjadi stabil dan likuid, diperlukan pula peraturan-peraturan yang mendukung.

Hubungan antara manusia, masyarakat dan hukum di Indonesia, dipengaruhi oleh penjajahan Belanda yang cukup lama. Budaya kolonial yang ditanamkan antara lain doktrin positivistik (hukum sifatnya normatif) yang kemudian mewarnai gaya hidup bangsa (Koentjaraningrat, 1990). Paradigma positivistik yang sudah terlanjur menjadi norma dan menguasai alam pikiran para birokrat, mengakibatkan pembentukan regulasi kerap dikuasai oleh benturan kepentingan (Siagian, 1994; Romli, 2008). Perhatian kerap lebih terpusat pada substansi topik yang diatur dan prosedur formal serta kurang memperhitungkan dampak regulasi tersebut terhadap kesejahteraan masyarakat. Biaya yang mungkin timbul karena regulasi yang tidak efektif, kurang mendapat perhatian.

Hak dan wewenang pembuatan regulasi adalah monopoli pemerintah sehingga melalui institusi yang diberi wewenang, pemerintah dapat menentukan regulasi dan kebijakan yang dapat melayani keinginannya. Dengan hak monopoli tersebut, regulator dapat mengubah, membatalkan, membuat regulasi yang tumpang tindih dan tidak konsisten dengan UndangUndang sehingga arah kebijakan menjadi tidak fokus. Regulator dapat mengabaikan tuntutan kebutuhan pasar atas kehadiran suatu konsep baru, atau badan usaha baru, karena 
kehadirannya dikhawatirkan akan mengancam konsep yang sudah ada dalam benaknya. Regulasi yang tidak berfungsi dengan baik dapat terjadi antara lain karena tiga hal. Pertama, regulasi tidak mengandung pesan yang dikehendaki oleh peraturan itu sendiri; kedua, regulasi yang dibuat tidak mengandung norma-norma untuk pelaksanaannya; dan ketiga, regulator tidak memantau efektifitas regulasi setelah implementasi (Rajagukguk, 2005).

Pengkajian hukum dalam perspektif ekonomi dapat dimanfaatkan untuk memberi masukkan kepada negara tentang hukum yang efisien, efektif dan bermanfaat bagi kesejahteraan mayarakat. Melalui pendekatan Hukum Ekonomi, prinsip ekonomi digunakan untuk menjelaskan dampak berlakunya suatu peraturan hukum bagi masyarakat, memperkirakan peraturan seperti apa yang paling efisien, sekaligus memprediksi bagaimana peraturan yang seharusnya diberlakukan (Posner, 1977). Untuk itu, teori dan metode empiris ekonomi diaplikasikan terhadap sistem hukum secara keseluruhan. Hukum dan ekonomi harus dipandang sebagai satu kesatuan dalam suatu sistem sosial. Hukum dan ekonomi merupakan sistem yang mengandung nilai-nilai yang hidup dalam masyarakat. Regulasi yang diperlukan adalah regulasi yang dapat menciptakan efisiensi dengan cara mengurangi eksternalitas ${ }^{3}$ negatif dan meningkatkan eksternalitas positif.

\section{PENUTUP}

Beberapa simpulan dapat ditarik dari tulisan ini. Pertama, alasan pemberian subsidi selalu seputar tingkat suku bunga yang tinggi, namun penyebab tingginya tingkat suku bunga, justru luput dari perhatian. Pemerintah harus memiliki kebijakan untuk mengatasi penyebab timbulnya masalah kurangnya hunian termasuk pasar primer tidak efisien, misal tingkat suku bunga tinggi, harga rumah yang mahal, pajak yang tinggi, kurangnya lembaga penyalur KPR, perizinan, penyertifikatan, dan ketersediaan dana jangka panjang. Kedua, pemerintah perlu memiliki strategi pembiayaan perumahan bagi MBR berdasarkan analisis biaya dan manfaat. Harus ada program pendamping subsidi berupa strategi yang secara bertahap melepas ketergantungan pada subsidi. Ketiga, menempatkan pengembangan sektor pembiayaan perumahan sebagai bagian dari pengembangan sistem keuangan negara untuk mencapai sasaran pembangunan nasional. Pemerintah harus memiliki komitmen untuk mendudukkan perumahan sebagai sektor prioritas dalam pembangunan ekonomi. Sistem keuangan harus dapat merangsang penciptaan dan peningkatan kepemilikan rumah baik di sektor formal maupun informal. Keempat, pemerintah harus menghapus hambatan yang menghalangi pertumbuhan KPR yang terjangkau oleh seluruh lapisan masyarakat, mendukung efisiensi dan pengelolaan risiko yang lebih baik, lebih membuka akses ke sumber pendanaan di pasar modal, mendorong peningkatan disiplin pasar. Selain itu, diperlukan regulasi untuk menerbitkan berbagai jenis instrumen pasar modal berbasis KPR dengan cara yang efisien dan hemat biaya. Terakhir, pembangunan ekonomi, pertumbuhan pasar perumahan dan pertumbuhan pasar modal harus dipandang sebagai tiga komponen yang saling memengaruhi, yang satu tidak lebih penting dari lainnya. Unsur yang menghubungkan ketiganya adalah efek penggandaan (multiplier effect) yang melekat pada industri perumahan. Multiplier effect dapat memberi dampak positif atau negatif, tergantung seberapa jauh kemampuan dalam mengelola dinamika sektor pembiayaan perumahan. Jika terdapat sinergi antara ketiga komponen tersebut, maka

3 Eksternalitas merujuk pada suatu keadaan di mana satu pihak memperoleh manfaat atau kerugian akibat dari suatu transaksi yang tidak melibatkan dirinya. 


\section{2 | Bina Ekonomi}

akan terbentuk suatu kekuatan baru yang dapat mendorong pertumbuhan ketiganya. Sebaliknya, jika terjadi kelambatan pertumbuhan pada salah satu komponen, maka komponen lain akan ikut tercemar dan terganggu pertumbuhannya. Oleh sebab itu, menciptakan interaksi yang harmonis antara kebijakan di sektor pembiayaan perumahan dan pasar modal, dengan sistem keuangan merupakan agenda penting yang perlu difasilitasi oleh pemerintah.

\section{DAFTAR PUSTAKA}

Arner, D. (2002). Emerging market economies and government promotion of securitization. Duke Journal of Comparative \& International Law, 12:505, 505-519.

Bank Indonesia. (n.d.). Sejarah Bank Indonesia: Perbankan periode 1997-1999. Unit Khusus Museum Bank Indonesia: Sejarah Bank Indonesia.

Bhattacharyay, B. (2011, Juli). Bond market development in Asia: An empirical analysis of major determinants. Asian Development Bank Institute WP Series No. 300, 1-31.

Cardin, J. S., Fleishman, D. M., \& Stamas, G. P. (1976). International secondary mortgage market: a proposal. Maryland Journal of International Law, 1(2), 172-195.

Carmichael, J., \& Pomerleano, M. (2002). The development and regulation of non-bank financial institutions. Washington D.C.: The World Bank.

Diamond, D. (1997, Juli). The promises and perils of interest ate subsidies: a survey of eight selected programs. US Agency for International Development.

Eichengreen, B., \& Hausmann, R. (1999, November). Exchange rates and financial fragility. National Bureau of Economic Reseach WP No. 7418, 1-54.

Eldin, Z. B., Mohieldin, M., \& Nasr, S. (2004, Desember). Prospects of mortgage markets in MENA countries: an analysis of financial, legal, and institutional aspects with emphasis on the Eqyptian case study. The Economic Research Forum WP Series No. 430.

Green, R. K., \& Wachter, S. M. (2007, Agustus). The Housing Finance Revolution. University of Pennsylvania Institute for Law and Economics Research Paper No. 09-37.

Koentjaraningrat. (1990). Pengantar Ilmu Antropologi. Jakarta: PT. Rineka Cipta.

Kompas.com. (2017, Oktober 20). Rasio KPR Indonesia Terendah di Dunia. Retrieved from Kompas.com: https://properti.kompas.com/read/2017/11/20/130000521/rasio-kprindonesia-terendah-di-dunia

Laeven, L. (2014, Desember). The development of local capital markets: Rationale and challenges. International Monetary Fund WP No. 14/234, 1-24.

Posner, R. A. (1977). Economic Analysis of Law (2nd ed.). Boston: Little Brown and Company.

Rajagukguk, E. (2005). Peran legislator dalam penyusunan peraturan perundang-undangan. Key-note Speech dalam Legal Drafting Course bagi anggota DPRD. Jakarta: Badan Kemitraan Ventura Universitas Indonesia. 
Romli, L. (2008, November). Masalah Reformasi Birokrasi. Jurnal Kebijakan dan Manajemen PNS, Pusat Pengkajian dan Penelitian Kepegawaian BKN, 2.

Siagian, S. (1994). Patologi Birokrasi Analisis, Identifikasi dan Terapinya. Jakarta: Ghalia Indonesia. 
94 | Bina Ekonomi

Halaman ini sengaja dikosongkan 